\title{
Litium-ontginning uit Zimbabwiese petaliet met behulp van ammoniumbifluoried
}

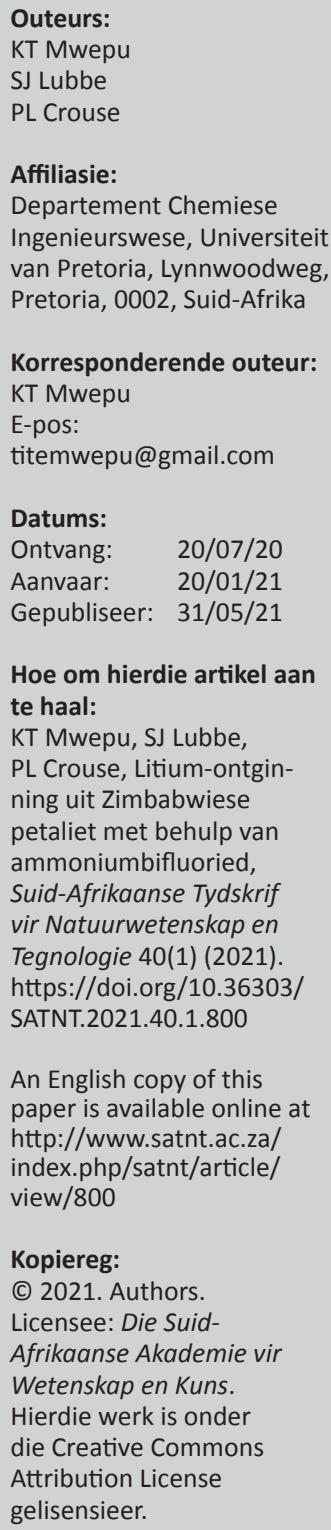

Hierdie studie behels die ontginning van gramhoeveelhede $\mathrm{Li}_{2} \mathrm{CO}_{3}$ uit Zimbabwiese petaliet, gemyn in die Bikita-gebied. Ekstraksie is gedoen met behulp van ammoniumbifluoried $(\mathrm{ABF})$, vanaf kamertemperatuur tot $600{ }^{\circ} \mathrm{C}$. ABF-vertering vervang die konvensionele hoëtemperatuurproses vir die omsetting van die mineraal na $\beta$-spodumeen voor suurbehandeling. Die ABF-proses vind by verrassende lae temperature plaas - selfs by kamertemperatuur word floddervorming waargeem as gevolg van die water wat tydens die reaksie vorm. Onder die smeltpunt van $\mathrm{ABF}$ is die hoofreaksieprodukte $\mathrm{LiF}, \mathrm{AlF}_{3^{\prime}}$ $\mathrm{K}_{2} \mathrm{NaAlF}_{6}$, en $\left(\mathrm{NH}_{4}\right)_{2} \mathrm{SiF}_{6}$. $\left(\mathrm{NH}_{4}\right)_{2} \mathrm{SiF}_{6}$ ontbind geredelik om ammoniak en gasagtige $\mathrm{SiF}_{4}$ te vorm. By laer temperature is die produkte kriolitioniet $\left(\mathrm{Li}_{3} \mathrm{Na}_{3} \mathrm{Al}_{2} \mathrm{~F}_{12}\right)$ and eukriptiet $\left(\mathrm{LiAlSiO}_{4}\right)$. Die fluoriedhoudende vastestowwe is swak oplosbaar in water. Die mengsel moet met swawelsuur gerooster word, en daarna word die sulfate met water uitgeloog; $99 \%$ suiwer litiumkarbonaat word relatief maklik uit die waterige fase herwin.

Sleutelterme: petaliet, vertering, loog, suiwering, presipitasie, litiumkarbonaat, Bikita Minerals

Lithium extraction from Zimbabwean petalite using ammonium bifluoride: Extraction of $\mathrm{Li}_{2} \mathrm{CO}_{3}$ from Zimbabwean petalite, from the Bikita deposit, was studied using ammonium bifluoride $(\mathrm{ABF})$ digestion at temperatures ranging from room temperature to $600{ }^{\circ} \mathrm{C}$, and gram quantities of ore. $\mathrm{ABF}$ digestion bypasses the conventional high-temperature conversion of the mineral to $\beta$-spodumene before acid roasting. The process reaction takes place at surprisingly low temperatures - even at room temperature with slurry formation due to the release of water. Below the melting point of $\mathrm{ABF}$, the main products are $\mathrm{LiF}, \mathrm{AlF}_{3}$, $\mathrm{K}_{2} \mathrm{NaAlF}_{6}$, and $\left(\mathrm{NH}_{4}\right)_{2} \mathrm{SiF}_{6}$. $\left(\mathrm{NH}_{4}\right)_{2} \mathrm{SiF}_{6}$ decomposes readily to form ammonia and gaseous $\mathrm{SiF}_{4}$. At higher temperature, the products are cryolithionite $\left(\mathrm{Li}_{3} \mathrm{Na}_{3} \mathrm{Al}_{2} \mathrm{~F}_{12}\right)$ and eucryptite $\left(\mathrm{LiAlSiO}{ }_{4}\right)$. The fluoride solids are not readily soluble in water and may be roasted in sulfuric acid at relatively mild conditions for a few tens of minutes, then water leached, with $99 \%$ pure lithium carbonate easily recovered from the aqueous phase.

Keywords: petalite, digestion, leaching, purification, precipitation, lithium carbonate, Bikita minerals

\section{Inleiding}

Litiumproduksie toon sedert die tweede wêreldoorlog bestendige groei. Meer onlangs is dit toeskryfbaar aan die gebruik van die element in litium-ioonbatterye vir elektriese voertuie en ander elektroniese toerusting (Hui et al., 2019). Hien-Dinh et al. (2015) voorspel 'n jaarlikse toename van $9.7 \%$ in litiumbehoefte. Kuang et al. (2018) voorspel 'n wêreldwye toename van $20 \%$ per jaar. Die mees algemene bronne van litium is soute in pekelwater, sowel as pegmatietminerale soos spodumeen, zinnwaldiet, lepidoliet, ambligoniet, en petaliet. Laasgenoemde word as die mees ekonomies lewensvatbare beskou (Garrett, 2004, Linnen et al., 2012, Aylmore et al., 2018). Petaliet is die mees gesogte litium-houdende mineraal, met 'n relatief hoë litiuminhoud en kan gebuik word om die element te ekstraheer as verbindings soos litiumkarbonaat $\left(\mathrm{Li}_{2} \mathrm{CO}_{3}\right)$, litiumchloried $(\mathrm{LiCl})$, en litiumfluoried ( $\left.\mathrm{LiF}\right)$ (Sitando and Crouse, 2012). Petaliet-neerslae word in Australië, Namibië, Kanada, Rusland, en Zimbabwe gevind. 
Litiumkarbonaat word as voorloper of voerstof vir ander litiumverbindings beskou (Jandová et al., 2010). LiF vind toepassing in spesialis UV-optika, keramieke, en in die aluminiumsmeltproses. $\mathrm{LiCl}$ is die voerstof vir die vervaardiging van Li-metaal via die elektrolise van $\mathrm{LiCl} /$ $\mathrm{KCl}$ by $450{ }^{\circ} \mathrm{C}$ en as vloeimiddel vir aluminium in motorvoertuigonderdele, sowel as droogmiddel in lugstrome.

Die konvensionele proses vir die ekstrahering van litium uit petaliet begin met die hittebehandeling van die erts teen $1100{ }^{\circ} \mathrm{C}$ vir ongeveer $2 \mathrm{~h}$ om die monokliniese kristalfase na suuroplosbare $\beta$-spodumeen om te skakel. Die proses is energie-intensief en gevolglik duur. (Guo et al., 2019, Hui et al., 2019, Rosales et al., 2013, Rosales et al., 2016). Die litium word as die sulfaat $\left(\mathrm{Li}_{2} \mathrm{SO}_{4}\right)$ saam met die kontaminante geëkstraheer, deur die $\beta$-spodumene in swawelsuur te rooster teen $300{ }^{\circ} \mathrm{C}$ vir $60 \mathrm{~min}$. Om 'n finale produk te berei, tipies litiumkarbonaat, word die waterige $\mathrm{Li}_{2} \mathrm{SO}_{4}$ gefiltreer om die onoplosbare silikate te verwyder, en die oplosbare kontaminante word deur selektiewe presipitasie as hidroksiede verwyder. Die presipitasie vind plaas deur die $\mathrm{pH}$ te verstel, gewoonlik deur die toevoeging van kalsiumkarbonaat of kalsiumhidroksied. As finale stap word litiumkarbonaat gepresipiteer deur die toevoeging van natriumkarbonaat. (Garrett, 2004, Hien-Dinh et al., 2015, Kondás et al., 2006, Guo et al., 2019, Sitando and Crouse, 2012, Wietelmann and Bauer, 2003).

Guo et al. (2019) het onlangs 'n alternief vir die hittebehandelingstap gepubliseer. Dit behels die gebruik van waterstoffluoried (HF) as verteringsmiddel vir die erts, in hulle geval $\alpha$-spodumeen. Hul resultate dui op die vorming van kriolitioniet $\left(\mathrm{Na}_{3} \mathrm{Li}_{2} \mathrm{Al}_{2} \mathrm{~F}_{12}\right)$, krioliet $\left(\mathrm{Na}_{3} \mathrm{AlF}_{6}\right)$, kalsiumfluoried $\left(\mathrm{CaF}_{2}\right)$, kaliumkrioliet $\left(\mathrm{K}_{2} \mathrm{AlF}_{5}\right)$ en aluminiumfluoried $\left(\mathrm{AlF}_{3}\right)$ wat in $\mathrm{H}_{2} \mathrm{SO}_{4}$ opgelos kan word, sowel as die fluoorsilikate $\left(\mathrm{Na}_{2} \mathrm{SiF}_{6}\right.$ or $\left.\mathrm{KNaSiF}_{6}\right)$. Slegs $\mathrm{HF}$ teen relatief lae temperature is in hul navorsing as fluoorbron gebruik.

HF is egter 'n gevaarlike suur om mee te werk, genereer toksiese verbindings, en prosesontwikkeling verg spesialiskennis (Andreev et al. 2007a, Rosales et al., 2013). HF is a gas by kamertemperatuur. In teenstelling is ammoniumbifluoried $(\mathrm{ABF})$ minder problematies as gevolg van sy relatiewe lae dampdruk, self bo sy smeltpunt.

'n Aantal artikels oor die oplossing van silikaatverbindings in ABF is reeds gepubliseer (Andreev et al., 2007a, Andreev et al., 2007b, Du Plessis et al., 2016, Nel et al., 2011, Nhlabathi et al., 2012, Retief et al., 2014). Hierdie navorsers gebruik $\mathrm{ABF}$ as bron van anhidriese HF (AHF) vir die behandeling van silikahoudende minerale by verskillende temperature en drukke. Retief et al. (2014) rapporteer die verwydering van silikon uit sirkonia-gebaseerde materiaal deur die vorming van ammoniumheptafluoorsirkonaat $\left(\left(\mathrm{NH}_{4}\right)_{3} \mathrm{ZrF}_{7}\right)$ en ammoniumheksafluoorsilikaat $\left(\mathrm{NH}_{4}\right)_{2} \mathrm{SiF}_{6}$. Laasgenoem- de kan maklik termies ontbind word om die skeiding te bewerkstellig. Nel et al. (2011) en Du Plessis et al. (2016) beskryf die reaksie tussen plasmagedissosieerde sirkoon en $\mathrm{ABF}$ sowel as ammoniumsuurfluoried ( $\mathrm{NH} 4 \times \mathrm{xHF}$, met $x>2$ ), en ontleed onderskeidelik die kinetika en die effek van die hoeveelheid HF inhoud. Nhlabathi et al. (2012) brei hierdie werk uit en verfyn die kinetika van Nel et al. (2011). Oor die algemeen word $\mathrm{ABF}$ in die gesmelte toestand gebruik, as 'n eenvoudige en relatief veilige HF-bron. Met die reaksie van topaas is die reaksieprodukte ammoniumheksafluoorsilikaat en ammoniumheksafluooraluminaat. (Andreev et al., 2007a):

$$
\mathrm{Al}_{2}\left(\mathrm{SiO}_{4}\right) \mathrm{F}_{2(\mathrm{~s})}+8 \mathrm{NH}_{4} \mathrm{~F} \cdot \mathrm{HF}_{(\mathrm{s})} \rightarrow\left(\mathrm{NH}_{4}\right)_{2} \mathrm{SiF}_{6(\mathrm{~g})}+4 \mathrm{H}_{2} \mathrm{O}_{(\mathrm{l})}+2\left(\mathrm{NH}_{4}\right)_{3} \mathrm{AlF}_{6(\mathrm{~s})}
$$

Ammoniumheksafluoorsilikaat en heksafluooraluminaat kan beide termies ontbind word volgens die reaksies:

$$
\begin{aligned}
& \left(\mathrm{NH}_{4}\right)_{2} \mathrm{SiF}_{6(\mathrm{~g})} \rightarrow \mathrm{SiF}_{4(\mathrm{~g})}+2 \mathrm{NH}_{3(\mathrm{~g})}+2 \mathrm{HF}_{(\mathrm{g})} \\
& \left(\mathrm{NH}_{4}\right)_{3} \mathrm{AlF}_{6(\mathrm{~s})} \rightarrow \mathrm{AlF}_{3(\mathrm{~s})}+3 \mathrm{NH}_{3(\mathrm{~g})}+3 \mathrm{HF}_{(\mathrm{g})}
\end{aligned}
$$

Die doelwit van die navorsing wat ons hier rapporteer, was om te bepaal of ABF gebruik kan word om litium uit petaliet te ekstraheer en of dit moontlik is om die termiese omsettingstap na $\beta$-spodumeen te omseil. Resulate van kleinskaalse laboratoriumeksperimente word gerapporteer. $\mathrm{ABF}$ is met petaliet gereageer en litiumkarbonaat is uit die die produkmengsel gesuiwer. Karakterisering van die reagent en materiaal is uitgevoer met behulp van induktiefgekoppelde plasma-optiese emissiespektroskopie (IGPOES), X-straal-diffraktometrie (XRD), and X-straal-fluoressensiespektrometrie (XRF).

\section{Eksperimenteel Materiale en reagense}

Die petalietbron was Bikita Minerals (Pvt) Ltd, Zimbabwe. Analitiese graad $\mathrm{NH}_{4} \mathrm{HF}_{2}$ en $\mathrm{H}_{2} \mathrm{SO}_{4}$ verkry vanaf Merck Chemicals, is gebruik. Gedeïniseerde water is in alle gevalle vir waterige toepassing benut.

\section{Instrumentasie}

Litium-analises is met behulp van 'n Spectro Arcos IGPOES uitgevoer. 'n Thermo ARL9400 XP XRF spektrometer is gebruik vir die elementanalise van die petalietkonsentraat. 'n PANalytical XRD is vir fasebepaling gebruik, met 'n Fefiltreerde $\mathrm{Co} \mathrm{K} \alpha$ as stralingsbron. Data is met behulp van $X^{\prime}$ Pert Highscore Plus sagteware verwerk. Die sagteware se verwysingsintensiteitsmetode is vir semi-kwantitatiewe analises benut (m. \%). 'n Hitachi 7300 is vir termogravimetriese analise (TGA) ingespan. Fourier-transformasieinfrarooispektrofotometrie (FTIR) is met behulp van 'n Perkin-Elmer Spectrum 100 uitgevoer. Vir weegwerk is 'n Mettler PM2000MC-skaal gebruik. pH-monitering is met 'n Adwa AD 111 uitgevoer. ' $\mathrm{n}$ Malvern Mastersizer 3000 is gebruik vir partikelgrootte-analise. 


\section{Eksperimentele metodiek}

Vertering is uitgevoer tussen 25 en $100^{\circ} \mathrm{C}$ deur die vermenging van $5 \mathrm{~g}$ petaliet $\left(\mathrm{LiAlSi}_{14} \mathrm{O}_{10}\right.$ ) met $37.5 \mathrm{~g} \mathrm{ABF}$ $\left(\mathrm{NH}_{4} \mathrm{HF}_{2}\right)$ in politetrafluooretileenhouers (PTFE). Die oond is voorverhit tot die gewensde temperatuur en die houers met die reaksiemengsel is in die oond geplaas vir die gespesifiseerde periode. Die reaksieperiode sluit dus verhitting van die material in. Om die reaksie te blus, is ' $n$ 3-5-keer oormaat water (per volume) by die reaksieproduk gevoeg om die wateroplosbare komponente op te los en is daarna gefiltreer. Die residu is teen $100{ }^{\circ} \mathrm{C}$ gedroog en daarna geweeg. Die onoplosbare produkte is met 'n $10 \%$ oormaat swawelsuur vermeng en gerooster teen $200{ }^{\circ} \mathrm{C}$ vir $30 \mathrm{~min}$. Die resulterende produk is afgekoel en in water opgelos teen $80^{\circ} \mathrm{C}$ vir $20 \mathrm{~min}$. Die reaksie tussen petaliet en $\mathrm{ABF}$ word deur Reaksie (4) onder gegee $\left(\Delta_{R x n} \mathrm{G}^{\circ}{ }_{298}=-13089.7\right.$ $\mathrm{kJ} \mathrm{mol}^{-1}$ ):

$$
\begin{aligned}
& \mathrm{Li}_{2} \mathrm{OAl}_{2} \mathrm{O}_{3} 8 \mathrm{SiO}_{2(\mathrm{~s})}+40 \mathrm{NH}_{4} \mathrm{HF}_{2(\mathrm{~s})} \\
& \rightarrow 2 \mathrm{LiF}_{(\mathrm{s})}+2 \mathrm{AlF}_{3(\mathrm{~s})}+8\left(\mathrm{NH}_{4}\right)_{2} \mathrm{SiF}_{6(\mathrm{~s})}+24 \mathrm{NH}_{4} \mathrm{~F}_{(\mathrm{aq})}+20 \mathrm{H}_{2} \mathrm{O}_{(\mathrm{l})}
\end{aligned}
$$

Gedurende die reaksie verdamp die water nie en dit word aangeneem dat die ammoniumfluoried óf ten volle óf gedeeltelik in die produkwater oplos. Let weer daarop dat die ammoniumheksafluoorsilikaat maklik termies ontbind word om $\mathrm{NH}_{3}(\mathrm{~g}), \mathrm{HF}$ (g) en $\mathrm{SiF}_{4}(\mathrm{~g})$ te lewer. Die suurroosterreaksie van die litiumfluoried/aluminiumfluoried met $\mathrm{H}_{2} \mathrm{SO}_{4}$ word beskryf deur Reaksie (5) hieronder $\left(\Delta_{R x n} \mathrm{G}_{298}^{\circ}=\right.$ $-6817.25 \mathrm{~kJ} \mathrm{~mol}^{-1}$ ) (Kuang et al., 2012).

$$
2 \mathrm{LiF}_{(\mathrm{s})}+2 \mathrm{AlF}_{3(\mathrm{~s})}+4 \mathrm{H}_{2} \mathrm{SO}_{4(\mathrm{l})} \rightarrow \mathrm{Li}_{2} \mathrm{SO}_{4(\mathrm{~s})}+\mathrm{Al}_{2}\left(\mathrm{SO}_{4}\right)_{3(\mathrm{~s})}+8 \mathrm{HF}_{(\mathrm{g})}
$$

Litiumsulfaat en aluminiumsulfaat is beide oplosbaar in water. Na filtrering word die flitraat gebruik om die litiumkonsentrasie met behulp van IGP-OES te bepaal. Alle eksperimente is in triplikaat uitgevoer.

Tydens die reaksies tussen $200{ }^{\circ} \mathrm{C}$ en $600{ }^{\circ} \mathrm{C}$ is stoigiometriese verhoudings $\mathrm{ABF}$ gebruik. Vertering is met $5 \mathrm{~g}$ petaliet $\left(\mathrm{LiAlSi}_{14} \mathrm{O}_{10}\right)$ en $12.26 \mathrm{~g}$ ABF in PTFE-houers gedoen. Die oond is tot die gewensde temperatuur verhit, die houers is daarbinne geplaas, en vir $2 \mathrm{~h}$ daar gehou. Daarna is die reaksieprodukte met water geblus en filtreer. Die vaste residue is teen $100{ }^{\circ} \mathrm{C}$ gedroog en daarna geweeg. Die onoplosbare produkte is in 'n oormaat swawelsuur gerooster. Die produk is daarna tot kamertemperatuur afgekoel, met water vermeng en opgelos by $80^{\circ} \mathrm{C}$. Die stoigiometriese reaksie tussen petaliet by hierdie temperature word deur Reaksie (6) onder gegee $\left(\Delta_{R x n} \mathrm{G}^{\circ}{ }_{298}=-10569.5\right.$ $\left.\mathrm{kJ} \mathrm{mol}{ }^{-1}\right)$ :

$$
\begin{aligned}
\mathrm{Li}_{2} & \mathrm{OAl}_{2} \mathrm{O}_{3} 8 \mathrm{SiO}_{2(\mathrm{~s})}+40 \mathrm{NH}_{4} \mathrm{HF}_{2(\mathrm{~s})} \\
& \rightarrow 23 \mathrm{Li}_{3} \mathrm{AlF}_{6(\mathrm{~s})}+43 \mathrm{AlF}_{3(\mathrm{~s})}+8\left(\mathrm{NH}_{4}\right)_{2} \mathrm{SiFF}_{(\mathrm{s})}+24 \mathrm{NH}_{3(\mathrm{~g})} \\
& +20 \mathrm{H}_{2} \mathrm{O}_{(\mathrm{g})}+24 \mathrm{HF}_{(\mathrm{g})}
\end{aligned}
$$

Die litium- en aluminiumfluoriede assosieer hier. Die temperatuur is hoog genoeg om enige ammoniumheksafluooraluminaat wat vorm, te ontbind, maar nie die ammoniumheksafluoorsilikaat nie. Ammoniumheksafluooraluminaat ontbind na $\mathrm{NH}_{3}(\mathrm{~g})$ en $\mathrm{HF}(\mathrm{g})$, en die vaste fluoried by $\sim 150{ }^{\circ} \mathrm{C}$, terwyl ontbind na $\mathrm{NH}_{3}(\mathrm{~g}), \mathrm{HF}(\mathrm{g})$ en $\mathrm{SiF}_{4}$ (g) by ongeveer $200{ }^{\circ} \mathrm{C}$ (sien Figuur 3 onder). Die suurroosterreaksie van litiumkrioliet/aluminiumfluoried met $\mathrm{H}_{2} \mathrm{SO}_{4}$ word in Reaksie (7) onder gegee $\left(\Delta_{R x n} \mathrm{G}_{298}^{\circ}=-14333.7\right.$ $\mathrm{kJ} \mathrm{mol}^{-1}$ ) (Kuang et al., 2012).

$$
2 \mathrm{Li}_{3} \mathrm{AlF}_{6(\mathrm{~s})}+2 \mathrm{AlF}_{3(\mathrm{~s})}+9 \mathrm{H}_{2} \mathrm{SO}_{4(\mathrm{l})} \rightarrow 3 \mathrm{Li}_{2} \mathrm{SO}_{4(\mathrm{~s})}+2 \mathrm{Al}_{2}\left(\mathrm{SO}_{4}\right)_{3(\mathrm{~s})}+18 \mathrm{HF}_{(\mathrm{g})}
$$

Die litiumhoudende filtraat word gebruik vir die bepaling van die litium- en kontaminantkonsentrasies met behulp van IGP-OES. Alle eksperimente is in triplikaat uitgevoer. Die resulterende oplossing is gesuiwer met $\mathrm{CaCO}_{3}$ en $\mathrm{Ca}(\mathrm{OH})_{2}$. $\mathrm{Li}_{2} \mathrm{CO}_{3}$ is met $\mathrm{Na}_{2} \mathrm{CO}_{3}$ gepresipiteer.

Die resultate by hoë temperature is ingewin as eksperimentreekse waar een veranderlike per reeks gevarieer is. Suurroostereksperimente is uitgevoer tussen $100{ }^{\circ} \mathrm{C}$ en $300{ }^{\circ} \mathrm{C}$, met roosterperiodes tussen $15 \mathrm{~min}$ en $45 \mathrm{~min}$, 'n suuroormaat tussen $0 \%$ en $20 \%$, loogroerspoed tussen $100 \mathrm{rpm}$ en $400 \mathrm{rpm}$, die vas-vloeiverhouding tussen 0.05 $\mathrm{g} \mathrm{mL}^{-1}$ en $0.13 \mathrm{~g} \mathrm{~mL}^{-1}$, en die loogperiode tussen $10 \mathrm{~min}$ en $40 \mathrm{~min}$.

\section{Resultate en bespreking Karakterisering van die erts}

Die kristallografiese analise van die erts, soos ontvang, word onder in Tabel 1 gegee. Die pegmatiet bestaan hoofsaaklik uit petaliet (in die $\alpha$-fase), met die geassosieerde

\begin{tabular}{|c|c|}
\hline Mineraalfase & (m. \%) \\
\hline Kwarts $\left(\mathrm{SiO}_{2}\right)$ & 6.1 \\
\hline Bikitaïet $\left(\mathrm{LiAlSi}_{2} \mathrm{O}_{6}\left(\mathrm{H}_{2} \mathrm{O}\right)\right.$ & 7.3 \\
\hline Petaliet $\left(\mathrm{LiAlSi}_{4} \mathrm{O}_{10}\right)$ & 79.9 \\
\hline Spodumeen $\left(\mathrm{LiAlSi}_{2} \mathrm{O}_{6}\right)$ & 2.1 \\
\hline Lepidoliet $\left(\mathrm{K}\left(\mathrm{Al}_{0.62} \mathrm{Li}_{0.38}\right)_{2} \mathrm{Li}_{0.92} \mathrm{Si} 4_{A} \mathrm{I}_{0.42} \mathrm{O}_{10}(\mathrm{OH})_{0.485} \mathrm{~F}_{1.51}\right)$ & 1.1 \\
\hline Albiet $\left(\mathrm{NaAlSi}_{3} \mathrm{O}_{8}\right)$ & 3.5 \\
\hline
\end{tabular}
minerale kwarts, bikitaïet, spodumeen, lepidoliet, en albiet.

Figuur 1 toon die partikel-grootte-verdeling van die erts, soos ontvang. $90 \%$ is kleiner as $74 \mu \mathrm{m}, 50 \%$ is onder $27 \mu \mathrm{m}$ en $10 \%$ is onder $3.5 \mu \mathrm{m}$.

Die elementsamestelling verskyn in Tabel 2 onder. Die analises is met beide XRF en IGP-OES uitgevoer.

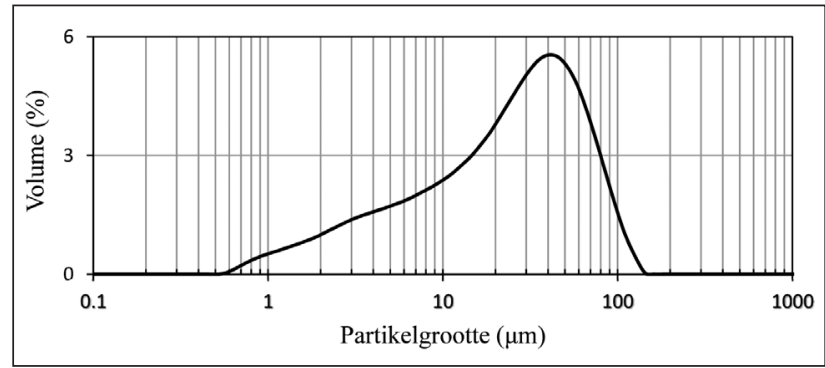

FIGUUR 1: Partikelgrootte-verdeling van die erts soos bepaal met ' $n$ Malvern Mastersizer 3000. 
TABEL 2: Chemiese samestelling van die petalieterts soos bepaal met IGP-OES en XRF.

\begin{tabular}{lcc}
\hline Komponent & IGP-OES (\%) & XRF (\%) \\
\hline $\mathrm{SiO}_{2}$ & - & 78.6 \\
$\mathrm{Al}_{2} \mathrm{O}_{3}$ & - & 17.8 \\
$\mathrm{Li}_{2} \mathrm{O}$ & 4.3 & - \\
$\mathrm{Fe}_{2} \mathrm{O}_{3}$ & - & 0.08 \\
$\mathrm{Na}_{2} \mathrm{O}$ & - & 0.20 \\
$\mathrm{MgO}$ & - & 0.15 \\
$\mathrm{~K} O$ & - & 0.14 \\
$\mathrm{CaO}$ & - & 0.09 \\
$\mathrm{Rb}_{2} \mathrm{O}$ & - & 0.03 \\
$\mathrm{MnO}$ & - & 0.01 \\
$\mathrm{P}_{2} \mathrm{O}_{5}$ & - & 0.01 \\
$\mathrm{ZrO}_{2}$ & - & 0.01 \\
$\mathrm{Cr}_{2} \mathrm{O}_{3}$ & - & 0.01 \\
$\mathrm{SrO}$ & - & $<0.01$ \\
$\mathrm{Co}_{3} \mathrm{O}_{4}$ & - & $<0.01$ \\
$\mathrm{SO}_{3}$ & - & 2.87 \\
$\mathrm{TOTAAL}$ & & 99.99
\end{tabular}

\section{Prosessering by temperature bo $100^{\circ} \mathrm{C}$}

\section{ABF-reaksie}

Die resultate vir hoë temperature, tussen $200^{\circ} \mathrm{C}$ en $600^{\circ} \mathrm{C}$, word in Figuur 2 gegee. Die X-straaldiffraktogramme van die ongereageerde erts verskyn in (a). Petaliet $\left(\mathrm{LiAlSi}_{4} \mathrm{O}_{10}\right)$ is die hoofkomponent, met tekens van kwarts en albiet $\left(\mathrm{NaAlSi}_{3} \mathrm{O}_{8}\right)$. In Figuur 2 (b) en (c), tussen $200{ }^{\circ} \mathrm{C}$ en $300^{\circ} \mathrm{C}$, toon die diffraktogramme met gedeeltelike vertering van die petaliet en die vorming van $\mathrm{LiF}$ en $\mathrm{AlF}_{3}$. By $400{ }^{\circ} \mathrm{C}$, $500{ }^{\circ} \mathrm{C}$ en $600{ }^{\circ} \mathrm{C}$ in Figuur 2 (d), (e) en (f), het die petaliet nagenoeg volledig gereageer. Dit lei tot die vorming van kriolitioniet $\left(\mathrm{Li}_{3} \mathrm{Na}_{3} \mathrm{Al}_{2} \mathrm{~F}_{12}\right)$.

Volgens Rosales et al. (2013) word die vorming van die kriolitioniet toegeskryf aan die verval van die struktuur tydens reaksie en die vrylating van die ione $\mathrm{Li}^{+}, \mathrm{Na}^{+}$en $\mathrm{Al}^{+}$ uit die petaliet en albiet om met die ABF te reageer, soos beskryf in die reaksie:

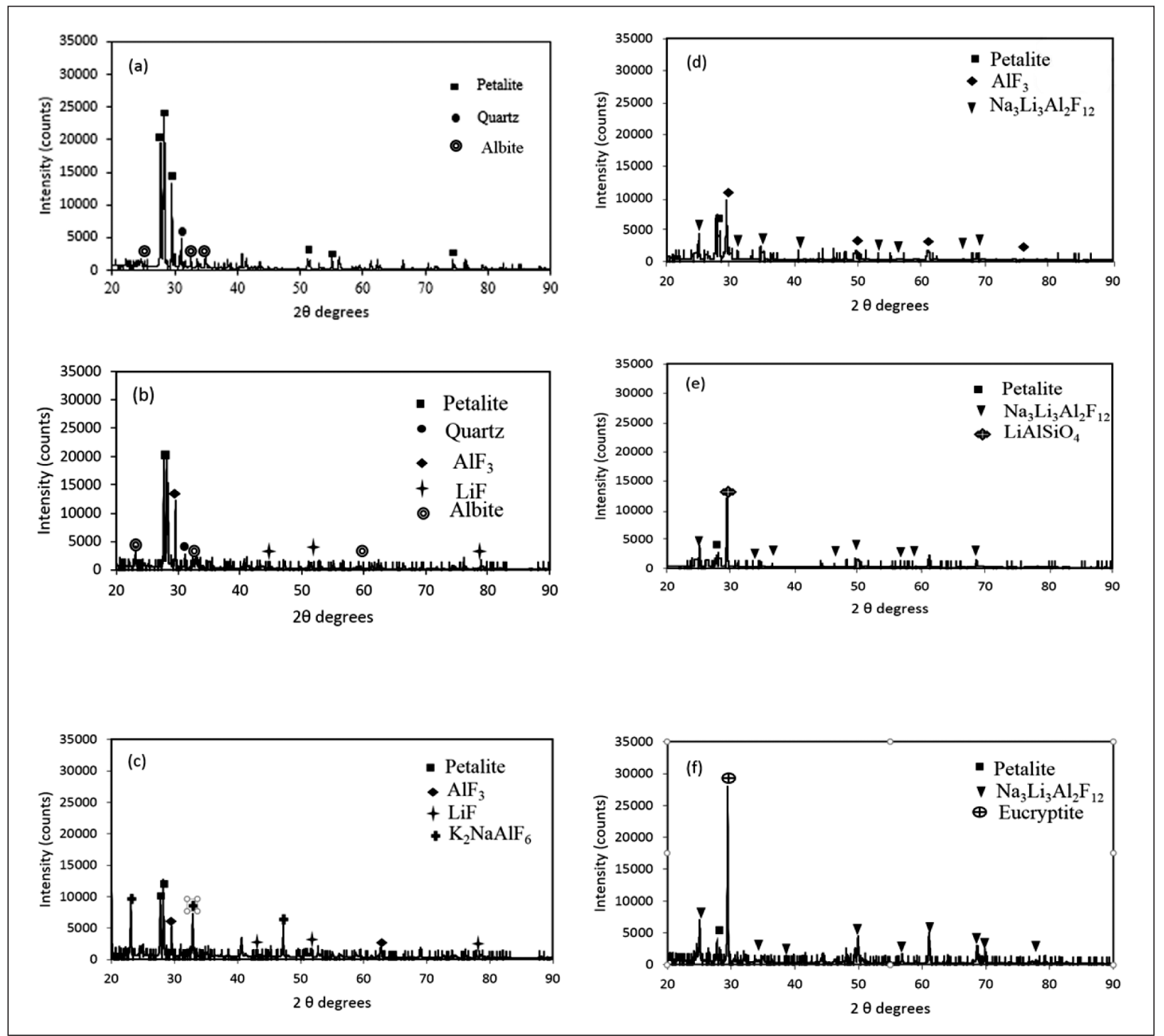

FIGUUR 2: X-straal-diffraktogramme van petaliet-residue verkry by die volgende toestande (erts/ABF-verhouding $1 / 1$ ): (a) Voor reaksie, (b) $200{ }^{\circ} \mathrm{C}$, (c) $300{ }^{\circ} \mathrm{C}$, (d) $400^{\circ} \mathrm{C}$, (e) $500^{\circ} \mathrm{C}$, en (f) $600^{\circ} \mathrm{C}$. 


$$
\begin{aligned}
& \mathrm{NaAlSi}_{3} \mathrm{O}_{8(\mathrm{~s})}+11 \mathrm{NH}_{4} \mathrm{HF}_{2(\mathrm{~s})} \rightarrow \mathrm{NaF}_{(\mathrm{s})}+\mathrm{AlF}_{3(\mathrm{~s})}+3\left(\mathrm{NH}_{4}\right)_{2} \mathrm{SiF}_{6(s)}+5 \mathrm{NH}_{3(\mathrm{~s})}+8 \mathrm{H}_{2} \mathrm{O}_{(\mathrm{l})} \\
& \mathrm{Li}_{3} \mathrm{AlF}_{6(\mathrm{~s})}+\mathrm{AlF}_{3(\mathrm{~s})}+3 \mathrm{NaF}_{(\mathrm{s})} \rightarrow \mathrm{Li}_{3} \mathrm{Na}_{3} \mathrm{Al}_{2} \mathrm{~F}_{12(\mathrm{~s})}
\end{aligned}
$$

Die verteringsproses is ook met dinamiese TGA bestudeer, by 'n konstante verhittingstempo van $10{ }^{\circ} \mathrm{C} / \mathrm{min}$. Die termogram word in Figuur 3 vertoon.

Sonder verdere ontwikkelingswerk is slegs 'n tentatiewe interpretasie moontlik. ABF smelt en begin ontbind in die gebied $115{ }^{\circ} \mathrm{C}$ tot $220^{\circ} \mathrm{C}$ (House and Engel, 1993). Tot by $\sim 150{ }^{\circ} \mathrm{C}$ is verliese toeskryfbaar aan ABF-ontbinding, tesame met water wat tydens die reaksie vrygelaat word. Ammoniumheksafluoorsilikaat vorm en verdamp tussen $230{ }^{\circ} \mathrm{C}$ en $370{ }^{\circ} \mathrm{C}$. Tussen $370{ }^{\circ} \mathrm{C}$ en $1000{ }^{\circ} \mathrm{C}$ bestaan slegs dievastefluoriede, naamlik kriolitioniet, aluminiumfluoried en eukriptiet.

FTIR-analises van die residue is na vertering uitgevoer, soos in Figuur 4 getoon. In Figuur 4 (a), die spektrum van ongereageerde erts, word $625 \mathrm{~cm}^{-1}$ toegeken aan die absorpsieband van die Si-Si binding, en die pieke by 1000 en $1100 \mathrm{~cm}^{-1}$ aan Si-O-Si en Si-O-modes onderskeidelik (Hoshino and Adachi, 2007). Hulle is steeds sigbaar by $200{ }^{\circ} \mathrm{C}$, maar verswak dramaties met styging van die

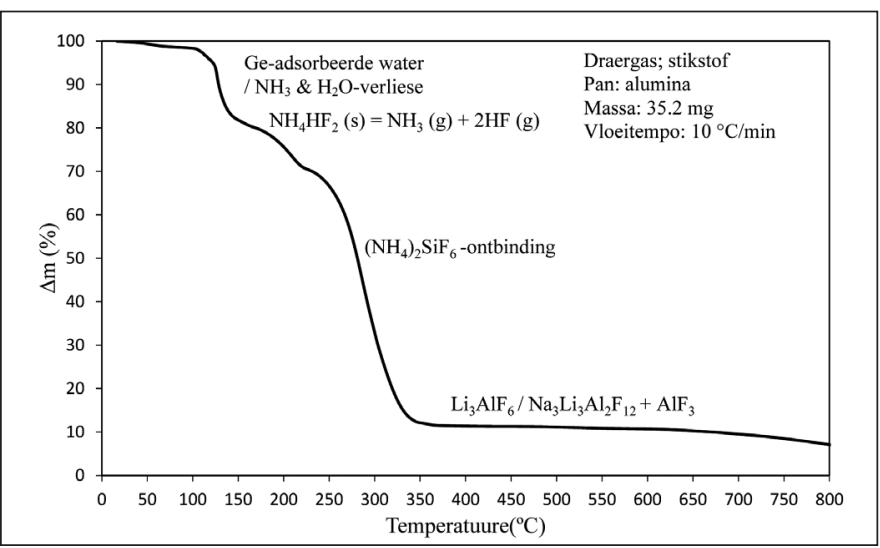

FIGUUR 3: TGA van 'n stoigiometriese mengsel van ABF en petaliet.

reaksietemperatuur, soos gesien in Figuur 4 (c) $300{ }^{\circ} \mathrm{C}$, (d) $400{ }^{\circ} \mathrm{C}$, (e) $500{ }^{\circ} \mathrm{C}$, en (f) $600{ }^{\circ} \mathrm{C}$. Die bande by $1443 \mathrm{~cm}^{-1}$ en $3290 \mathrm{~cm}^{-1}$, waargeneem tot met $400{ }^{\circ} \mathrm{C}$, word aan N-H-buig en -strek toegereken (Kabacelik and Ulug, 2008), 'n aanduiding van die teenwoordigheid van nie-ontbinde ammoniumfluoormetalate. By temperature bo $500{ }^{\circ} \mathrm{C}$ is die IR-aktiwiteit onder $900 \mathrm{~cm}^{-1}$. Die pieke by ongeveer $580 \mathrm{~cm}^{-1}$ word aan die vorming van $\mathrm{AlF}_{6}^{3-}$ toegereken, in die vorm van $\mathrm{AlF}_{3}$. (Duke et al., 1990).

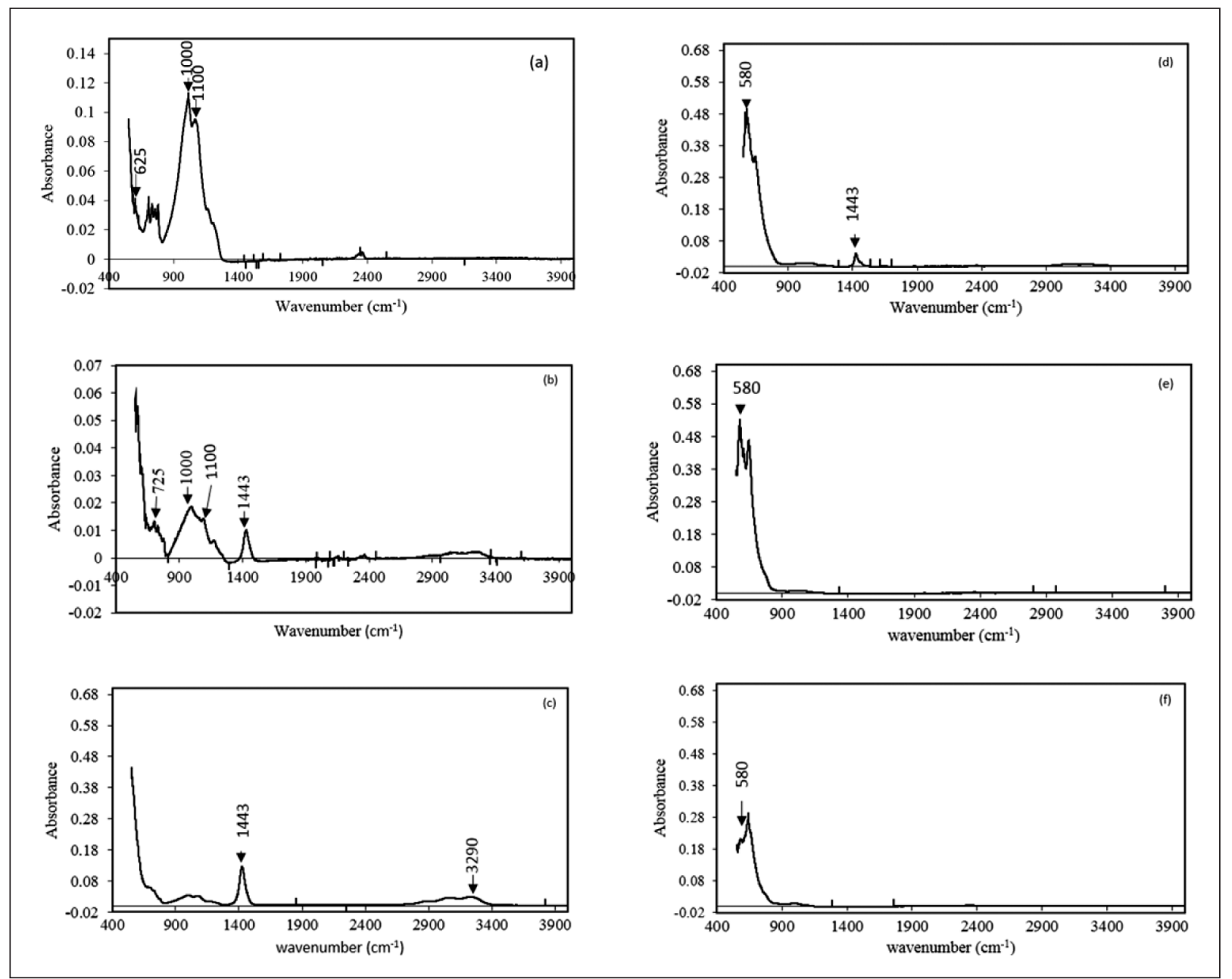

FIGUUR 4: FTIR-spektra van ongereageerde petaliet en residue na vertering by verskillende temperature: (a) Suiwer petaliet, (b) $200{ }^{\circ} \mathrm{C}$, (c) $300{ }^{\circ} \mathrm{C}$, (d) $400^{\circ} \mathrm{C}$, (e) $500^{\circ} \mathrm{C}$, en (f) $600^{\circ} \mathrm{C}$. 
Die finale produk is met water gewas om van al die wateroplosbare verbindings ontslae te raak, gefiltreer en daarna by $100{ }^{\circ} \mathrm{C}$ gedroog. Die onoplosbare produkte is met 'n oormaat swawelsuur vermeng en teen $300{ }^{\circ} \mathrm{C}$ vir $60 \mathrm{~min}$ gerooster. Die produk van hierdie proses - nou'n gekonsentreerde flodder - is afgekoel tot kamertemperatuur. Water is daarna bygevoeg en die mengsel is by $80{ }^{\circ} \mathrm{C}$ vir $20 \mathrm{~min}$ opgelos.

Toename in die temperatuur van $200{ }^{\circ} \mathrm{C}$ tot $600{ }^{\circ} \mathrm{C}$ verhoog die reaksie-effektiwiteit soos in Figuur 5 aangetoon word. In Figuur 2 kan gesien word dat ammoniumfluoorsilikaat na vertering ontbind. Tussen $400{ }^{\circ} \mathrm{C}$ en $600{ }^{\circ} \mathrm{C}$ is die ekstraksie van litium bo $95 \%$. 'n Temperatuur van $500{ }^{\circ} \mathrm{C}$ word aanbeveel deur oorweging van beide koste en effektiwiteit.

Die litium is met 'n oormaat suur en hoë loogtemperature geëkstraheer om volledige oplossing te verseker. Die spesifieke toestande is in verdere detail ondersoek. Die resultate word in die paragrawe wat volg bespreek.

\section{Suur-roosterproses}

\section{Die effek van suuroormaat}

'n Aantal eksperimente om die effek van suuroormaat te ondersoek, is uitgevoer. Die suuroormaat is tussen 0 en $20 \%$ verander om optimale toestande te bepaal. Die resultate word in Figuur 6 onder gegee. 'n $5 \%$ oormaat lewer $96.5 \%$ oormaat, met slegs 'n marginale verbetering bo hierdie punt.

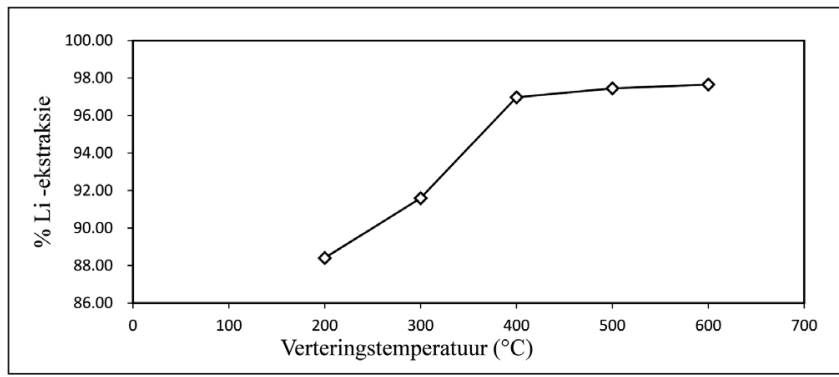

FIGUUR 5: Effek van reaksietemperatuur op litium-ekstraksie vir die volgende toestande: $25 \%$ oormaat suur, roostertemperatuur $300{ }^{\circ} \mathrm{C}$, waterloogtemperatuur $90{ }^{\circ} \mathrm{C}$, loogtyd $60 \mathrm{~min}$, roerspoed $400 \mathrm{rpm}$ en vasvloeistofverhouding $0.05 \mathrm{~g} \mathrm{~mL}^{-1}$.

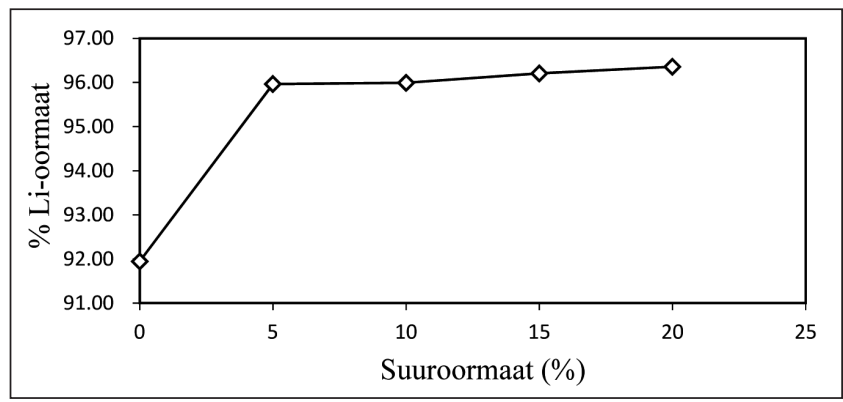

FIGUUR 6: Effek van die oormaat swawelsuur by die volgende toestande: $500^{\circ} \mathrm{C}$ verteringstemperatuure, roostertemperatuur $300{ }^{\circ} \mathrm{C}$, waterloogtemperatuur $90^{\circ} \mathrm{C}$, loogperiode $60 \mathrm{~min}$, roerspoed $400 \mathrm{rpm}$ en vas-vloeistofverhouding 0.05 $\mathrm{g} \mathrm{mL}^{-1}$.

\section{Effek van temperatuur}

Die effek van roostertemperatuur is by $100^{\circ} \mathrm{C}, 150{ }^{\circ} \mathrm{C}$, and $200{ }^{\circ} \mathrm{C}$ ondersoek. Volgens die resultate in Figuur 7 lewer 'n verhoogde temperatuur die verwagte, hoewel klein, verhoging in ekstraksie-effektiwiteit. 'n Verhoging vanaf $100{ }^{\circ} \mathrm{C}$ tot $200^{\circ} \mathrm{C}$ lei tot 'n $1 \%$ verbetering. Die verskil tussen resultate by $100{ }^{\circ} \mathrm{C}$ en $200{ }^{\circ} \mathrm{C}$ is dus marginaal. ' $\mathrm{n}$ Roostertemperaturr van $100{ }^{\circ} \mathrm{C}$ lewer 'n $96.5 \%$ opbrengs en is aanvaarbaar vir praktiese doeleindes.

\section{Effek van roosterperiode}

Die resultate aangedui in Figuur 8 wys dat' $n$ roosterperiode van 30 min 'n goeie werkspunt is. 'n Ekstraksie-effektiwitiet van $96.5 \%$ word hier verkry.

\section{Loog}

\section{Effek van roersnelheid}

Die effek van agitasie is by ' $n$ konstante rooster- en loogtemperatuur, konstante suuroormaat, identiese vasvloeiverhouding en loogperiode ondersoek, met die roerspoed wat tussen $100 \mathrm{rpm}$ en $300 \mathrm{rpm}$ verander is. Soos die data in Figuur 9 aantoon, het die roerspoed 'n beduidende effek. Bo $300 \mathrm{rpm}$ word die beperkende effek van massa-oordrag geëlimieer en die ekstraksie styg van $\sim 92 \%$ tot $\sim 96 \%$. Massa-oordrag verwys na diffusie deur die stagnante grenslagie wat elke partikel omring en wat deur hoë roerspoed gestroop word. Bo $300 \mathrm{rpm}$ is die verbetering in opbrengs nie beduidend nie.

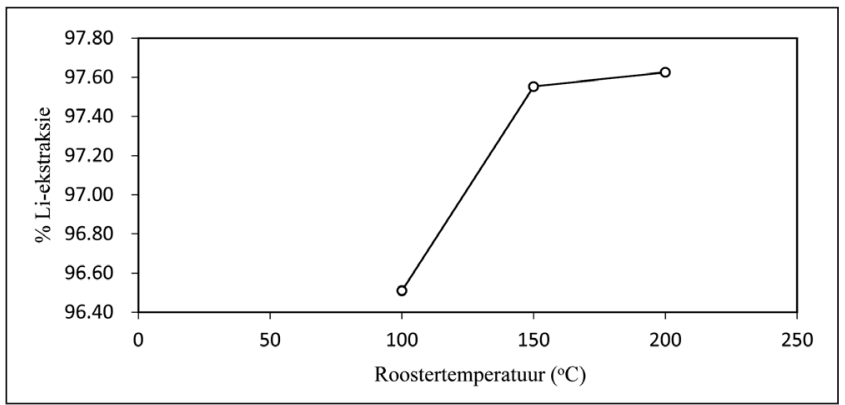

FIGUUR 7: Effek van roostertemperatuur by die volgende toestande: suuroormaat $5 \%$, roosterperiode 60 minutes, waterloogtemperatuur $90{ }^{\circ} \mathrm{C}$, loogperiode 60 minutes, roerspoed $400 \mathrm{rpm}$ en vas-vloeistofverhouding 0.05 $\mathrm{g} \mathrm{mL}^{-1}$.

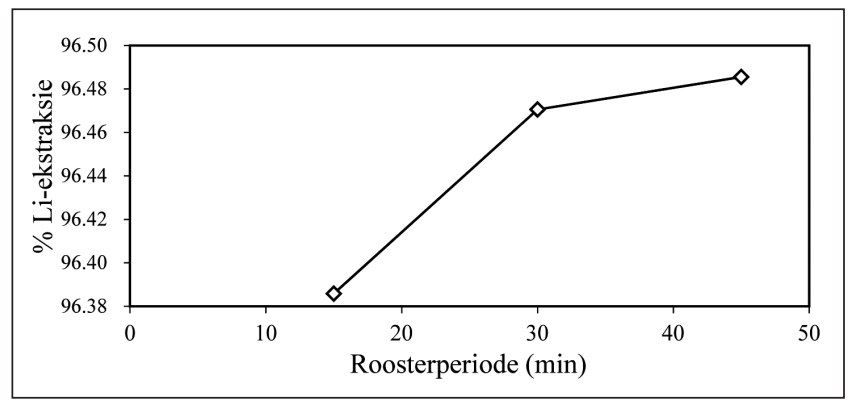

FIGUUR 8: Effek van roosterperiode op Li-ekstraksie-effektiewiteit by die volgende toestande: $500{ }^{\circ} \mathrm{C}$ verteringstemperatuur, suuroormaat $5 \%$, roostertemperatuur $100{ }^{\circ} \mathrm{C}$, waterloogtemperatuur $90^{\circ} \mathrm{C}$, loogperiode $60 \mathrm{~min}$, roerspoed $400 \mathrm{rpm}$ en vas-vloeistofverhouding $0.05 \mathrm{~g} \mathrm{~mL}^{-1}$. 


\section{Effek van van die vastestof-tot-vloeistofver- houding}

Die effek van die verhouding tussen die hoeveelheid vastestof en vloeistof is ondersoek (die vloeistof is water en die eenhede $\mathrm{g} \mathrm{mL}^{-1}$ word gebruik). Die resultate word in Figuur 10 geïllustreer. 'n Verlaging van die vas-vloeistofverhouding lei to 'n verlaging van die viskositeit en gevolglik meer effektiewe agitasie en verbeterde massaoordrag na die reaskie-oppervlakke. Vir die verhoudingspunte $0.1,0.067$ en $0.05 \mathrm{~g} \mathrm{~mL}^{-1}$ bly die opbrengs nagenoeg konstant; $97 \%$, $96.7 \%$, en $95.6 \%$ onderskeidelik. Bo hierdie waardes neem die opbrengs af. 'n Verhouding van $0.1 \mathrm{~g}$ $\mathrm{mL}^{-1}$ word as 'n goeie kompromie beskou.

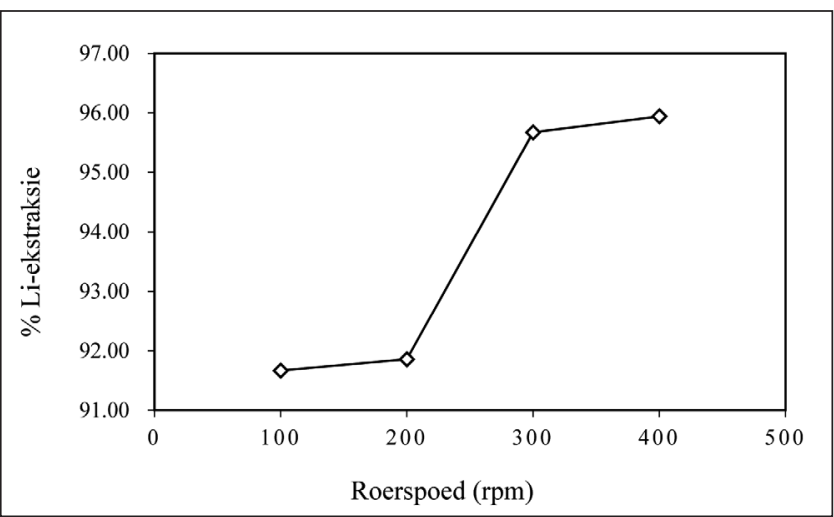

FIGUUR 9: Effek van roerspoed op die effektiwiteit van litium-ekstraksie by die volgende toestande: $500{ }^{\circ} \mathrm{C}$ verteringstemperatuur, suuroormaat $5 \%$, roostertemperatuur $100^{\circ} \mathrm{C}$, waterloogtemperatuur $90^{\circ} \mathrm{C}$, loogperiode 60 minute, en vas-vloeistofverhouding $0.05 \mathrm{~g} \mathrm{~mL}^{-1}$.

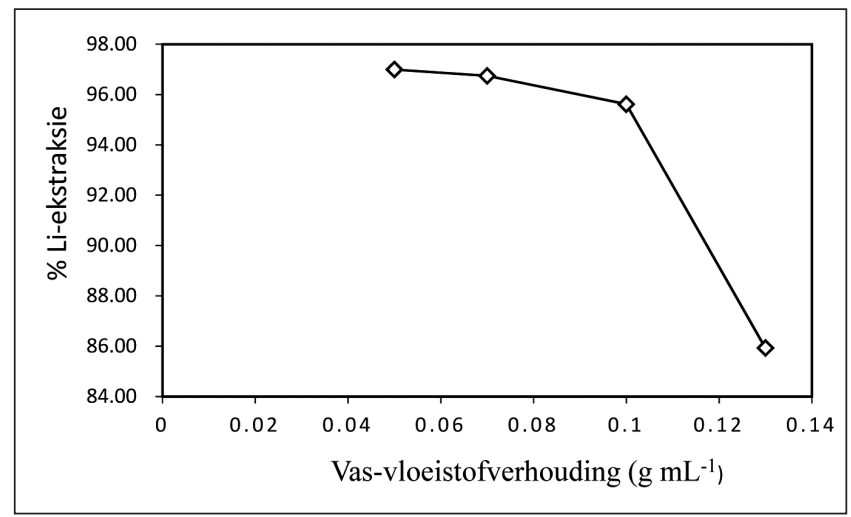

FIGUUR 10: Effek van die vastestof-tot-vloeistofverhouding op die effektiwiteit van litium-ekstraksie by die volgende toestande: $500{ }^{\circ} \mathrm{C}$ verteringstemperatuur, suuroormaat $5 \%$, roostertemperatuur $100{ }^{\circ} \mathrm{C}$, loogtemperatuur $90{ }^{\circ} \mathrm{C}$, loogperiode $60 \mathrm{~min}$, roerspoed $300 \mathrm{rpm}$.

\section{Effek van loogtyd en temperatuur}

Die opbrengs is bepaal by $40{ }^{\circ} \mathrm{C}$ en $80{ }^{\circ} \mathrm{C}$ by ' $\mathrm{n}$ vasvloeiverhouding van $0.1 \mathrm{~g} \mathrm{~mL}^{-1}$ en teen 'n roerspoed van $300 \mathrm{rpm}$. Dit is duidelik uit die data wat in Figuur 11 voorgelê word, dat temperatuur 'n beduidende rol speel. Die opbrengs bly nagenoeg konstant as $\sim 96 \%$ teen $80{ }^{\circ} \mathrm{C}$ tussen 10 en $40 \mathrm{~min}$. By $40{ }^{\circ} \mathrm{C}$ is die opbrengs baie swakker, en varieer tussen $60 \%$ en $80 \%$ as funksie van tyd. Die voorgestelde bedryfsparameters is $30 \mathrm{~min}$ teen $80^{\circ} \mathrm{C}$.

\section{Suiwering van die oplossing}

Tabel 3 illustreer die verandering in onsuiwerhede na oplossing en selektiewe presipitasie. Kalsiumkarbonaat $\left(\mathrm{CaCO}_{3}\right)$ is effektief vir die presipitasie van aluminium en yster. Kalsiumhidroksied $\mathrm{Ca}(\mathrm{OH})_{2}$ is ingelyks effektief vir die verwydering van magnesium. $\mathrm{Na}_{2} \mathrm{CO}_{3}$ word gebruik vir die verwydering van die oormaat $\mathrm{Ca}$ voor die presipitasie van $\mathrm{Li}_{2} \mathrm{CO}_{3}$. Die $\mathrm{Li}_{2} \mathrm{CO}_{3}$-oplossing wat volg, word verdamp tot 'n konsentrasie van $5 \mathrm{~g} \mathrm{~L}^{-1}$; hierna word die $\mathrm{pH}$ verander tot $\sim 8$. Die litium-verliese oorhoofs is nagenoeg $12 \%$.

\section{Herwinning en karakterisering van litiumkarbo- naat}

Die gesuiwerde loogvloeistof is by $95-100{ }^{\circ} \mathrm{C}$ verdamp voor die presipitasie van $\mathrm{Li}_{2} \mathrm{CO}_{3}$. Die hoë temperatuur is nodig aangesien die oplosbaarheid van litiumkarbonaat verlaag by verhoogde temperatuur (Wietelmann and Bauer, 2003). $\mathrm{Na}_{2} \mathrm{CO}_{3}$ is die mees effektiewe presipiteringsagent; die verhoogde karbonaatkonsentrasie skuif die ewewig na die onopgelosde vaste $\mathrm{Li}_{2} \mathrm{CO}_{3}$.' $n 15 \%$ warm oplossing $\mathrm{Na}_{2} \mathrm{CO}_{3}$ is by die verhitte loogvloeistof gevoeg

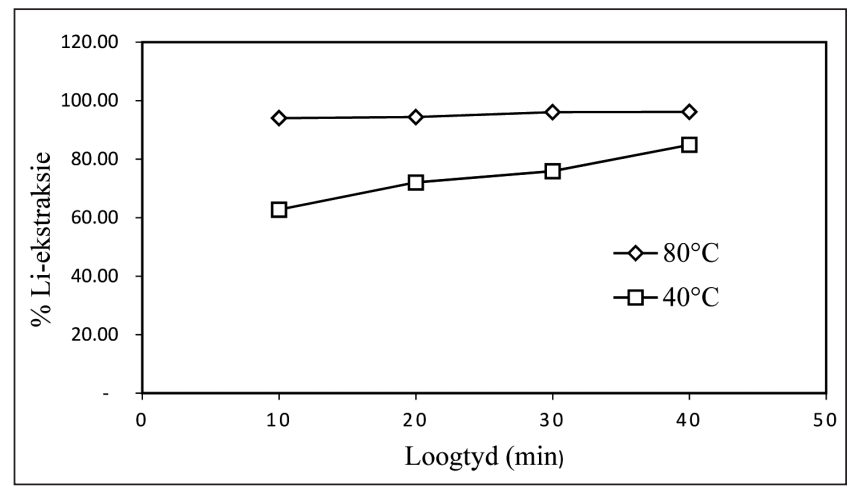

FIGUUR 11: Effek van die loogtemperatuur by die volgende toestande: $500{ }^{\circ} \mathrm{C}$ verteertemperatuur, suuroormaat $5 \%$, roostertemperatuur $100{ }^{\circ} \mathrm{C}$, vas-vloeistofverhouding $0.1 \mathrm{~g} \mathrm{~mL}^{-1}$, roerspoed $300 \mathrm{rpm}$.

TABEL 3: Elementkonsentrasie tydens die suiweringsproses.

\begin{tabular}{|c|c|c|c|c|c|c|c|c|}
\hline \multirow[t]{2}{*}{ Oplossing } & \multirow[t]{2}{*}{$\mathrm{pH}$} & \multicolumn{7}{|c|}{ Elemenkonsentrasie $\left(\mathrm{mg} \mathrm{L}^{-1}\right)$} \\
\hline & & $\mathrm{Li}$ & $\mathrm{Ca}$ & K & $\mathrm{Na}$ & Al & $\mathrm{Fe}$ & $\mathrm{Mg}$ \\
\hline Oorspronklike loogvloeistof & 1.5 & 4864.6 & 161.2 & 252.2 & 752.6 & 11887.9 & 50.1 & 13.9 \\
\hline Toevoeging van $\mathrm{CaCO}_{3}$ en $\mathrm{Ca}(\mathrm{OH})_{2}$ & 10.7 & 3866.5 & 2241.5 & 202.1 & 616.7 & 566.2 & 1.9 & 1.5 \\
\hline Toevoeging van $\mathrm{Na}_{2} \mathrm{CO}_{3}$ & 11.2 & 3453.5 & $<0.03$ & 216.1 & 1601.9 & $<0.001$ & $<0.01$ & $<0.02$ \\
\hline Gekonsentreerde loogvloeistof & 8.00 & 6022.2 & 50.2 & 513.4 & 6580 & 12.5 & $<0.01$ & 2.1 \\
\hline Moederloogvoeistof & & 2486.1 & & & & & & \\
\hline
\end{tabular}


om wit $\mathrm{Li}_{2} \mathrm{CO}_{3}$ te laat uitkristalliseer. Die presipitaat is met warm water gewas om die $\mathrm{Na}_{2} \mathrm{SO}_{4}$ te verwyder. Van die natriumsulfaat kristalliseer wel, maar word deur die warm wasproses opgelos en word verwyder tydens filtrering (Lagos and Becerra, 2005). Die relevante chemiese reaksie vir die presipitasie met behulp van $\mathrm{Na}_{2} \mathrm{CO}_{3}$ is:

$$
\mathrm{Li}_{2} \mathrm{SO}_{4(\text { aq) }}+\mathrm{Na}_{2} \mathrm{CO}_{3(\text { aq) }} \rightarrow \mathrm{Li}_{2} \mathrm{CO}_{3(\mathrm{~s})}+\mathrm{Na}_{2} \mathrm{SO}_{4(\text { aq })}
$$

'n $86 \%$ opbrengs is tipies.

Die produk is met behulp van XRD gekarakteriseer en met 'n kommersiële produk vergelyk. Soos uit die diffraktogramme in Figuur 12 duidelik is, die spektra identies, met ons produk wat effens beter kristalliniteit toon.
Die morfologie van kommersiële $\mathrm{Li}_{2} \mathrm{CO}_{3}$-poeier (Figuur 13) is met ons gesintetiseerde produk (Figuur 14) vergelyk, met gebruikmaking van SEM. Beide die gevalle toon prismatiese kristalle met pinakoïdale termineringsvlakke. Die kristalle tydens hierdie studie voorberei, is kleiner en gevolglik meer opeengehoop. Die blyk dat hoër litiumkonsentrasies in die beginoplossing tot kleiner partikels lei. 'n Verklaring is dat die hoër Li-beginkonsentrasies in hoër konsentrasies kernvormingsetels tot gevolg het.

Tabel 4 rapporteer die suiwerheid van die gesintetiseerde produk. Die suiwerheid is $98.9 \%$. Natrium is die hoofkontaminant alhoewel die konsentrasievlak verlaag kan word met addisionele was van die finale produk.

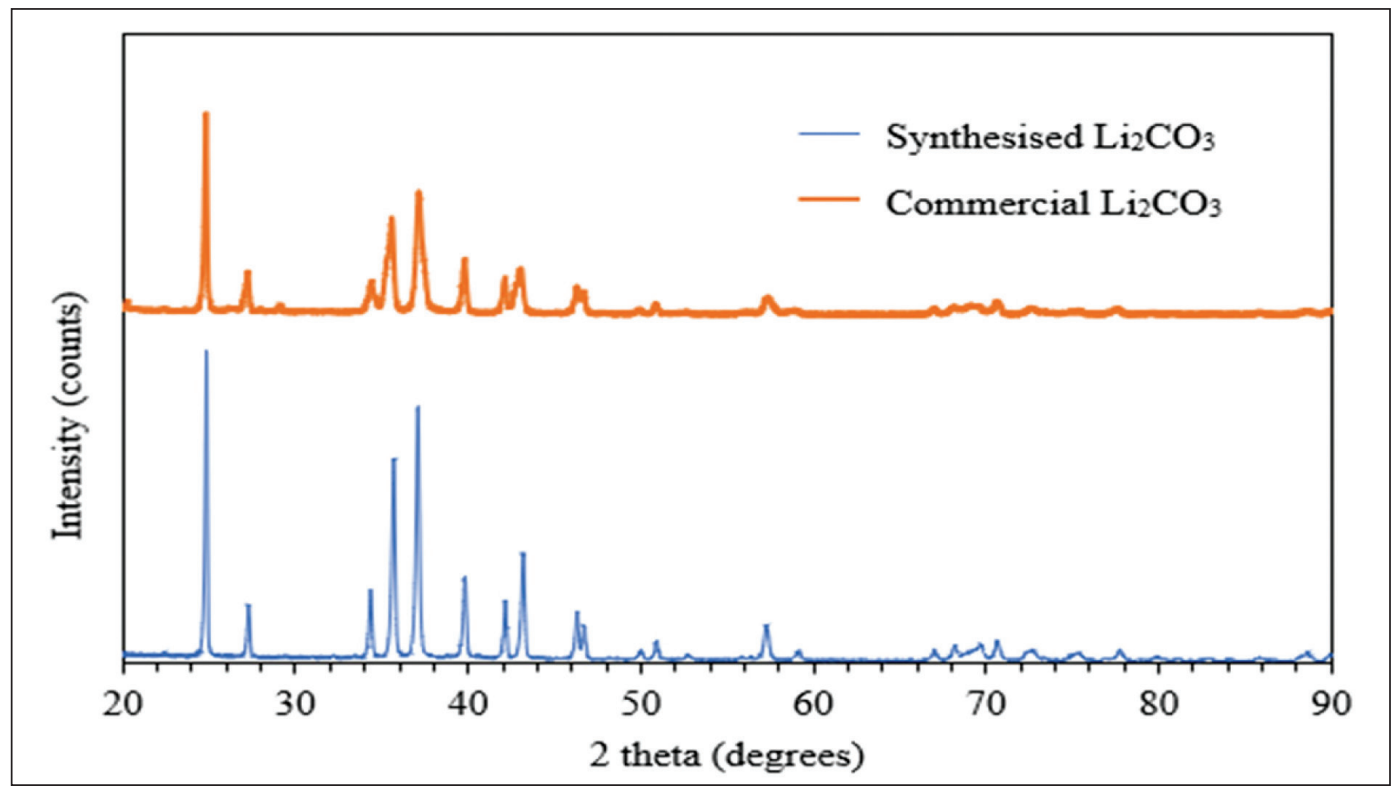

FIGUUR 12: X-straaldiffraktogramme van gesintetiseerde en kommersiële $\mathrm{Li}_{2} \mathrm{CO}_{3}$.

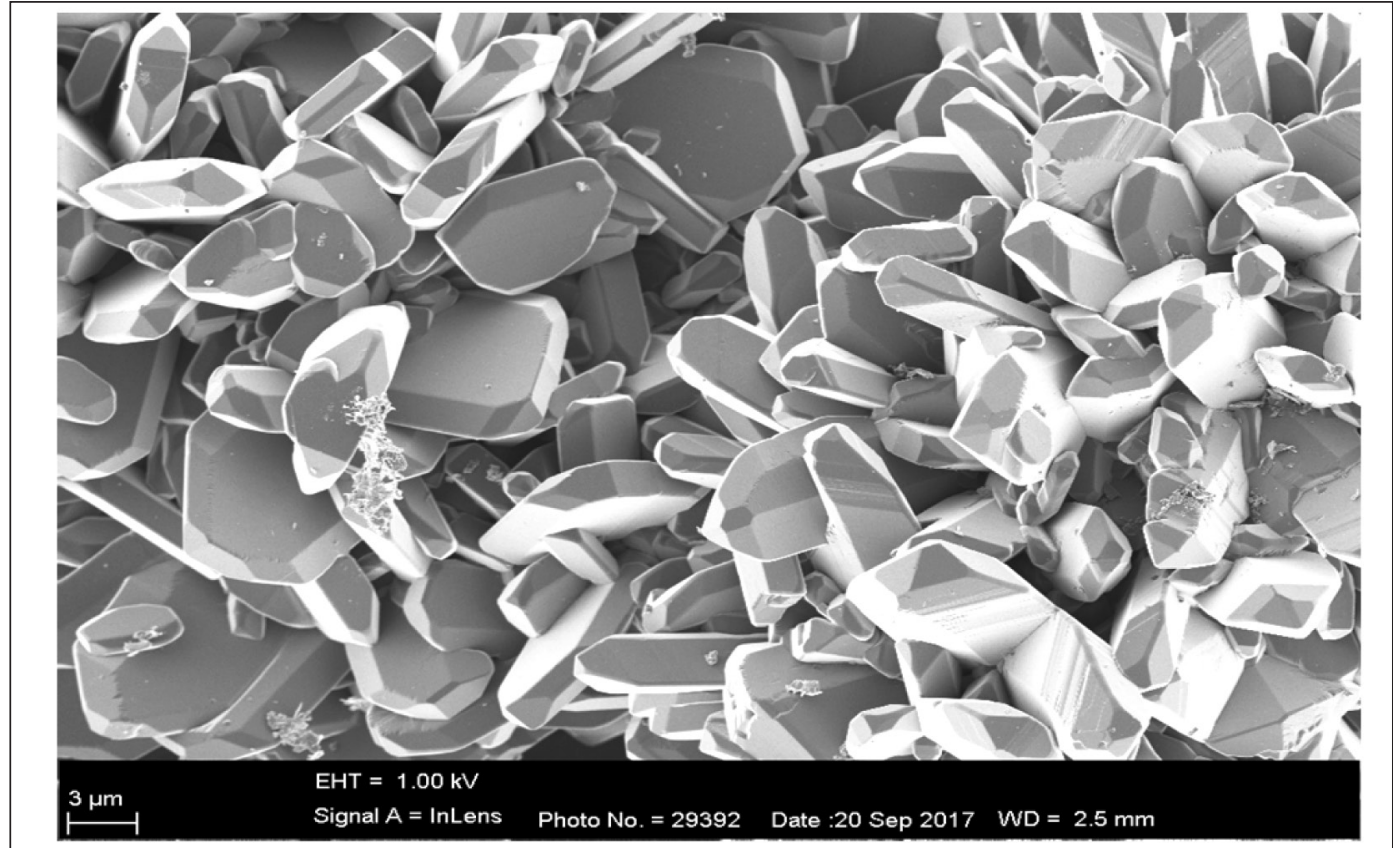

FIGUUR 13: Sekondêre-elektron-SEM-beeld van kommersiële $\mathrm{Li}_{2} \mathrm{CO}_{3}$. 


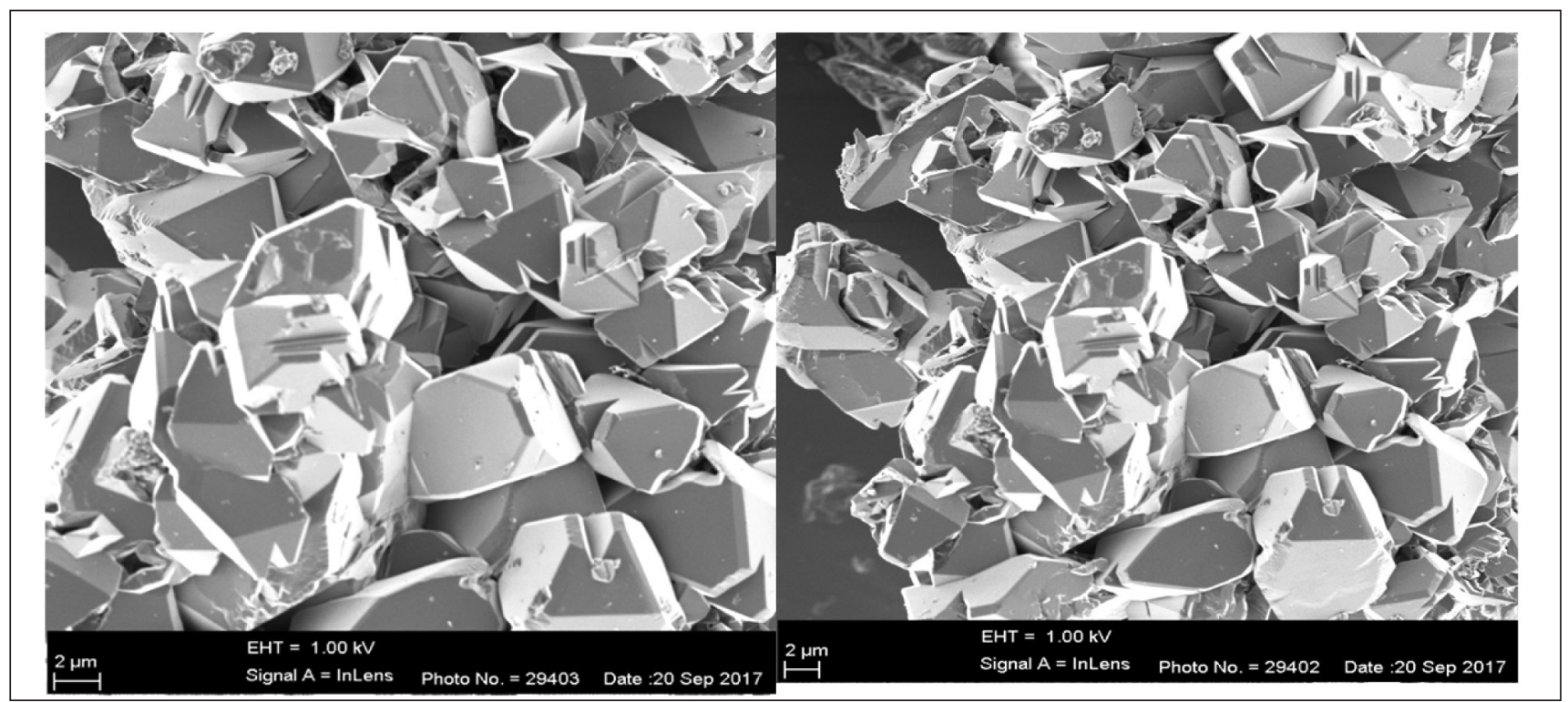

FIGUUR 14: Sekondêre-elektron-SEM-beeld van die gesintetiseerde $\mathrm{Li}_{2} \mathrm{CO}_{3}$.

TABEL 4: Samestalling van gesintetiseerde $\mathrm{Li}_{2} \mathrm{CO}_{3}$

\begin{tabular}{llllllll}
\hline $\mathrm{Li}_{2} \mathrm{CO}_{3}$ suiwerheid $(\mathrm{m} \%)$ & \multicolumn{7}{c}{ Hoofonsuiwerhede $(\mathrm{m} \%)$} \\
\hline & $\mathrm{Ca}$ & $\mathrm{Al}$ & $\mathrm{Fe}$ & $\mathrm{K}$ & $\mathrm{Mg}$ & $\mathrm{Na}$ \\
98.9 & 0.5 & $<0.05$ & $<0.01$ & $<0.02$ & $<0.01$ & 0.6 \\
\hline
\end{tabular}

\section{Die ABF-reaksie onder $100{ }^{\circ} \mathrm{C}$}

Tydens die eksperimentele werk bo gerapporteer, is die waarneming gemaak dat die ABF-petalietreaksie reeds by kamertemperatuur plaasvind. Verdere eksperimente is gevolglik uitgevoer om die minimum reaksietemperatuur te bepaal. ' $\mathrm{n}$ Driemaaloormaat van $\mathrm{ABF}$ is gebruik. In hierdie eksperimente is die temperature konstant gehou by $25^{\circ} \mathrm{C}, 50^{\circ} \mathrm{C}, 75^{\circ} \mathrm{C}$, en $100{ }^{\circ} \mathrm{C}$, elk vir $15,30,60,120,180$ and $240 \mathrm{~min}$. Die ertsomsetting $\left(\alpha=m / m_{0}\right)$ is bereken uit die verhouding van die litiummassa $(m)$ herwin uit die sulfaatoplossing by tyd $t$ en die litiumaanvangsmassa $\left(m_{0}\right)$ in die monster. Die verteringsprodukte is weereens in swawelsuur gerooster. Die produk van hierdie proses is in water opgelos by $80^{\circ} \mathrm{C}$, en die litiuminhoud $(m)$ is met IGPOES bepaal. Die resultate word in Figuur 15 onder weergegee.

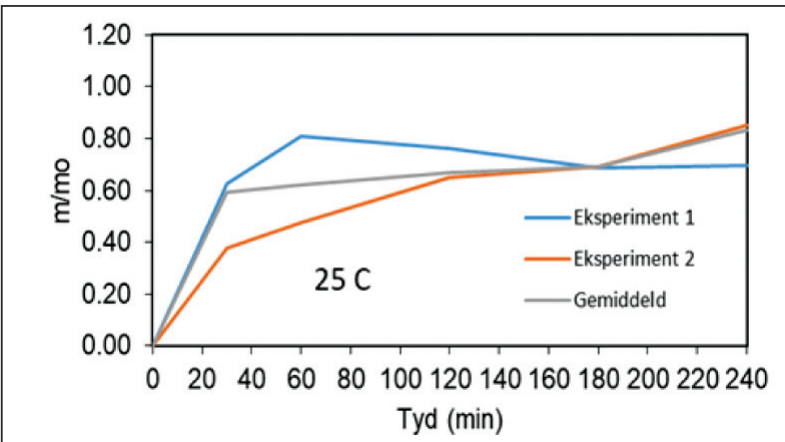

(a)

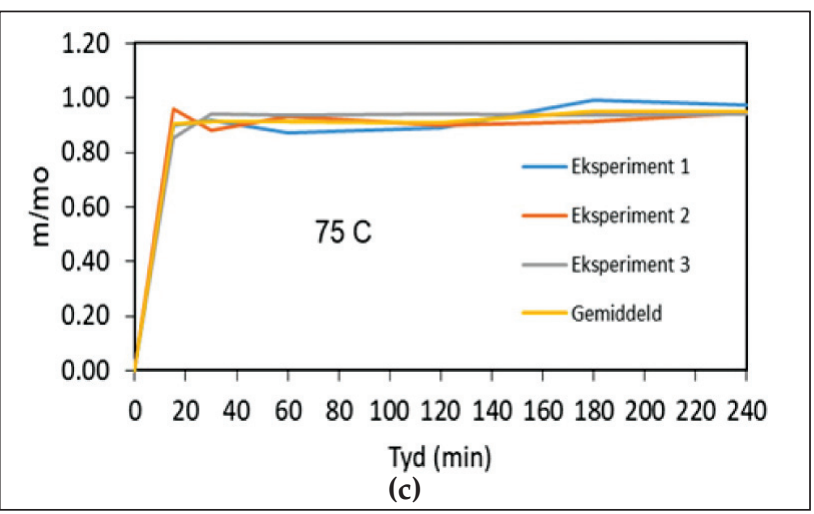

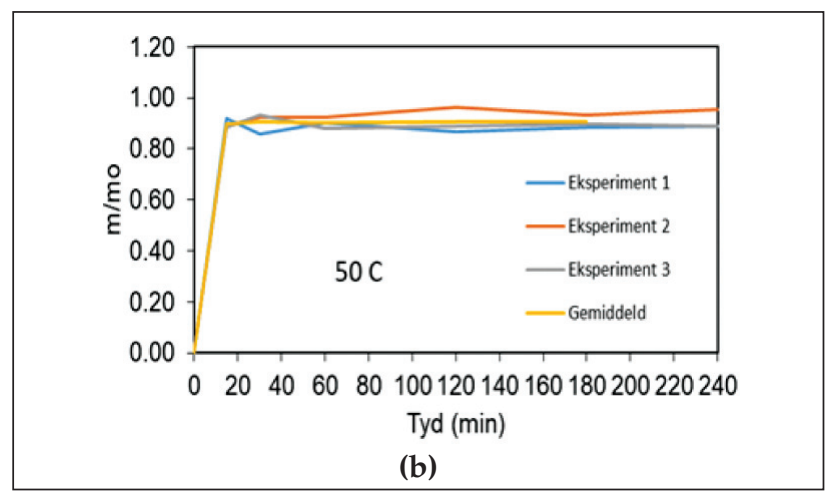

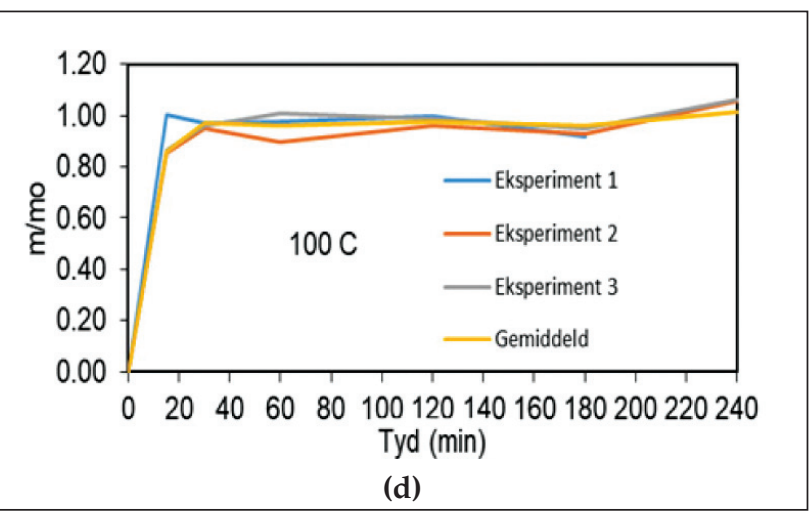


Dit is belangrik om kennis te neem dat die kroesie met die vermengde reagense in elke geval by kamertemperatuur was toe dit in die voorverhitte moffeloond geplaas is (behalwe natuurlik vir die lopies by $25^{\circ} \mathrm{C}$ waar 'n oond nie nodig was nie). Die reaksietyd wat rapporteer word, sluit dus die verhitting van die kroesie en die inhoud in. Reaksieperiodes is dus aanduidend eerder as eksak. Soos uit Figuur 15 (a) waargeneem kan word, begin die reaksie reeds by $25{ }^{\circ} \mathrm{C}$. Na 60 min bly die omsetting konstant by $\sim 75 \%$. Figuur 15 (b) tot (d) wys dat die tyd na ewewig afneem en dat die omsetting toeneem by hoër temperature. $\mathrm{Na} 20 \mathrm{~min}$ by $50{ }^{\circ} \mathrm{C}$ is die petaliet-omsetting konstant, nagenoeg $91 \%$. Figuur 15 (c) wys dat by $75^{\circ} \mathrm{C}$ die omsetting tot $\sim 95 \%$ verhoog. Figuur 15 (d) dui dat die reaksie volledig is by $100^{\circ} \mathrm{C}$.

Figuur 16 som die hoofbevindinge uit Figuur 15 op, en illustreer die finale omsettingsgraad en tyd om hierdie ewewig te bereik as funksie van temperatuur. Die waardes vir $\alpha_{\text {Maks' }}$ die gemiddelde maksimum omsettingsgraad, is bereken uit die finale drie datapunte vir elke datastel vir elke ekpserimentreeks by elke temperatuur. Die foutbalkies verteenwoordig twee standaardafwykings van die gemiddelde waarde; dit is ' $n$ betroubaarheidsinterval van $2 \sigma$, oftewel $68 \%$. Die gemiddelde tyd om ewewig te bereik is bereken uit die eerste datapunt van elke reeks waar, binne eksperimentele fout, ewewig bereik is. Die foutbalkies in hierdie geval is $2 \sigma$-visuele ramings. Ons oorhoofse gevolgtrekking is dat 'n tempratuur van $100{ }^{\circ} \mathrm{C}$ vir 'n periode van $30 \mathrm{~min}$ veilige proses-ontwerpspesifikasies is.

Die reaksies wat hier bestudeer is, begin vir alle temperature in die vaste fase. Onmiddellik na vermenging van die vaste reagense word floddervorming en die evolusie van ammoniak waargeneem, soos deur Reaksie (6) voorspel word. Behalwe vir kamertemperatuur word maksium omskakeling binne 40 min bereik. Soos reeds genoem, styg die maksimum omskakeling as funksie van temperatuur en volledige reaksie vind by $100{ }^{\circ} \mathrm{C}$ plaas. Ons gevolgtrekking is dat die reaksie nie diffusiebeheerd is soos verwag nie. Dit blyk dat ' $n$ termodinamiese ewewig bereik word in die semi-waterige omgewing van die flodderproduk. Figuur 17 (a) en (b) ilustreer die X-straaldiffraktogramme van die petaliet voor en na reaksie by $100{ }^{\circ} \mathrm{C}$. Na reaksie word die vaste fluoriedprodukte waargeneem.

Herwinning van die finale litiumkarbonaat is relatief eenvoudig soos in die hoëtemperatuurwerk bo, by wyse van 'n swawelsuurroosterproses, waterloging, en selektiewe presipitasie.

\section{Gevolgtrekking}

Ammoniumbifluoried is ' $n$ effektiewe en eenvoudige veteerder vir petaliet, en 'n alternatief vir die hoë-temperatuurbehandeling van die $\alpha$-spodumeen mineraal na $\beta$-spodumeen. Die proses vind by verbasende lae temperature plaas, selfs by kamertemperatuur waar floddervorming waargeneem word as gevolg van die vorming van water. Onder die smeltpunt van $\mathrm{ABF}$ is die hoofprodukte $\mathrm{LiF}, \mathrm{AlF}_{3^{\prime}}, \mathrm{K}_{2} \mathrm{NaAlF}_{6}$, en $\left(\mathrm{NH}_{4}\right)_{2} \mathrm{SiF}_{6} .\left(\mathrm{NH}_{4}\right)_{2} \mathrm{SiF}_{6}$ ontbind geredelik om ammoniak en gasagtige $\mathrm{SiF}_{4}$ te vorm. Die produkte is kriolitioniet $\left(\mathrm{Li}_{3} \mathrm{Na}_{3} \mathrm{Al}_{2} \mathrm{~F}_{12}\right)$ en eukriptiet $\left(\mathrm{LiAlSiO}{ }_{4}\right)$ by hoër temperature. Die vaste fluoriede is nie wateroplosbaar nie and moet in swawelsuur gerooster word en in water geloog word om $99 \%$ suiwer litiumkarbonaat uit die waterige fase te lewer.

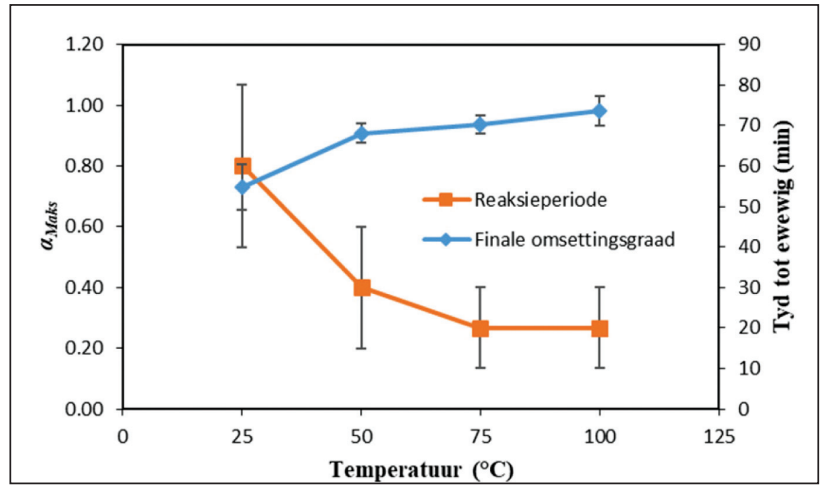

FIGUUR 16: Finale omsettingsgraad $\left(\alpha_{\text {max }}\right)$ van Zimbabwese petaliet by verskillende temperature en ooreenstemmende tyd om $\alpha_{\max }$ te bereik.

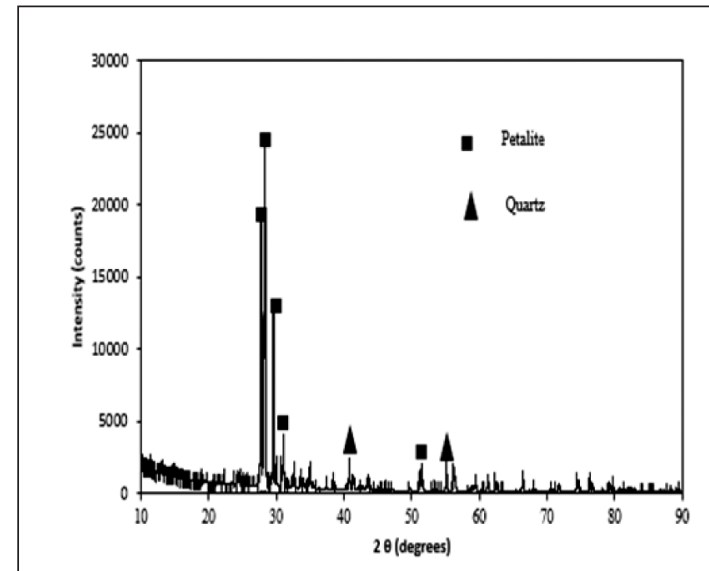

(a)

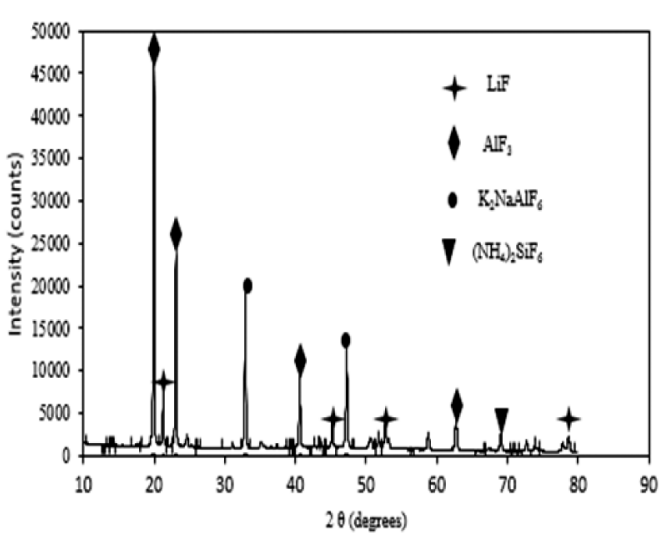

(b)

FIGUUR 17: X-straaldiffraktogramme van Zimbabwiese petaliet (a) voor en (b) na reaksie met $\mathrm{NH}_{4} \mathrm{HF}_{2}$. 
Ekonomiese lewensvatbaarheid is nie in hierdie stadium oorweeg nie. Heel waarskynlik sal die belangrikste oorweging die ongewensde silikon- en aluminiumfluoried wees. Die ammoniumheksafluoorsilikaat ontbind geredelik na ammoniak, AHF, en $\mathrm{SiF}_{4}$. Die ammoniak en en AHF kan in beginsel herwin en hergebruik word as ABF. Silikontetrafluoried, ook 'n ongewensde uitvloeisel in die fosfaatindustrie in die vorm van fluosilisielsuur, kan met'n metaal gereduseer word om silikonmetaal te vorm. Die metaalfluoried kan op sy beurt as voorloper gebruik word, saam met byvoorbeeld die metaaloksied, vir die elektrolitiese vervaardiging van die element. Suksevolle gebruik van die neweprodukte kan deurslaggewend wees in die suksesvolle kommerialisering van hierdie navorsingsresultate.

\section{Dankbetuigings}

Ons bedank Bikita Minerals (Pvt) Ltd vir die petalieterts wat vir hierdie navorsing gebruik is, die DST se Fluorochemical Expansion Initiative (FEI) vir finansiële ondersteuning, en Dr. Kokkie Swanepoel vir idees rondom die hergebruik van afvalstrome.

\section{Verwysings}

Andreev, V.A., Buynovskiy, A.S., Andreev, A.A., Dyachenko, A.N. 2007a. Topaz concentrate desiliconization with ammonium bifluoride. Bulletin of the Tomsk Polytechnic University, 311, 27-31.

Andreev, V.A., Buynovskiy, A.S., Dyachenko, A.N., Kraidenko, R.I. 2007b. Studying the utilization techniques of ammonium heksafluorosilicate. Bulletin of the Tomsk Polytechnic University, 311, 31-34.

Aylmore, M.G., Merigot, K., Rickard, W.D. 2018. Assessment of a spodumene ore by advanced analytical and mass spectrometry techniques to determine its amenability to processing for the extraction of litium. Minerals Engeneering, 119, 137-148. https://doi.org/10.1016/j.mineng.2018.01.010.

Du Plessis, W., Pienaar, A.D., Postma, C.J., Crouse, P.L. 2016. Effect of the value of $x$ in NH4F. XHF on the digestion of plasma-dissociated zircon. International Journal of Minereral Processing, 147, 43-47. https://doi.org/10.1016/j. minpro.2016.01.002.

Duke, C.V., Miller, J.M., Clark, J.H., Kybett, A.P. 1990. 19F mas NMR and FTIR analysis of the adsorption of alkali metal fluorides onto alumina. Journal of molecular catalysis, 62, 233-242. https://doi.org/10.1016/0304-5102(90)85216-5.

Garrett, D.E., 2004. Handbook of litium and natural calcium chloride, UK, vol.I.Elsevier Book,Elsevier Ltd. https://doi.org/10.1016/B978-0122761522/50038-4.

Guo, H., Kuang, G., Wan, H., Yang, Y., YU, H.-Z., Wang, H.D. 2019. Enhanced acid treatment to extract litium from lepidolite with a fluorine-based chemical method. Hydrometallurgy, 183, 9-19. https://doi.org/10.1016/j. hydromet.2018.10.020.

Hien-Dinh, T.T., Luong, V.T., Gieré, R., Tran, T. 2015. Extraction of litium from lepidolite via iron sulphide roasting and water leaching. Hydrometallurgy, 153, 154-159. https://doi.org/10.1016/j.hydromet.2015.03.002
Hoshino, D., Adachi, S., 2007. Stain Etching Characteristics of Silicon (001) Surfaces in Aqueous HF/ K2Cr2O7 Solutions. Journal of The Electrochemical Society, 154, E139-E144. https://doi.org/10.1149/1.2767852.

House, J.E., Engel, D.A. 1983. Decomposition of ammonium bifluoride and the proton affinity of the bifluoride ion. Thermochimica Acta, 66, 343-345. https:// doi.org/10.1016/0040-6031(93)85045-B.

Hui, G., Yu, H.Z., Zhou, A.A. 2019. Kinetics of leaching litium from $\alpha$-spodumene in enhanced acid treatment using $\mathrm{HF} / \mathrm{H} 2 \mathrm{SO} 4$ as medium. Transactions of Nonferrous Metals Society of China, 29, 407-415. https://doi.org/10.1016/ S1003-6326(19)64950-2.

Jandová, J., Dvořák, P., Vu, H.N. 2010. Processing of zinnwaldite waste to obtain Li2CO3. Hydrometallurgy, 103, 12-18.https://doi.org/10.1016/j. hydromet.2010.02.010.

Kabacelik, I., Ulug, B. 2008. Further investigation on the formation mechanisms of (NH4) 2SiF6 synthesized by dry etching technique. Applied Surface Science, 254, 1870-1873. https://doi.org/10.1016/j.apsusc.2007.08.064.

Kondás, J., Jandová, J., Nemeckova, M. 2006. Processing of spent Li/MnO2 batteries to obtain Li2CO3. Hydrometallurgy, 84, 247-249. https://doi.org/10.1016/j. hydromet.2006.05.009.

Kuang, G., Chen, Z.B., Guo, H., Li, M.H. 2012. Litium Extraction Mechanism from $\alpha$-Spodumene by Fluorine Chemical Method. Advanced Materials Research, 524-527, 2011-2016.https://doi.org/10.4028/www.scientific.net/AMR.524527.2011.

Kuang, G., Liu, Y., Li, H. 2018. hydrometExtraction of litium from $\beta$-spodumene using sodium sulfate solution. Hydrometallurgy, 177, 49-56. https://doi. org/10.1016/j.hydromet.2018.02.015

Lagos, S., Becerra, R. 2005. Methodology for the recovery of litium from litium titanate. Journal of Nuclear Materials, 347, 134-139. https://doi.org/10.1016/j. jnucmat.2005.08.013.

Linnen, R.L., Van Lichtervelde, M., Černý, P. 2012. Granitic pegmatites as sources of strategic metals. Elements, 8, 275-280. https://doi.org/10.2113/ gselements.8.4.275

Nel, J.T., Du Plessis, W., Nhlabathi, T.N. 2011. Reaction kinetics of the microwave enhanced digestion of zircon with ammonium acid fluoride. Journal of Fluorine Chemistry, 132, 258-262. https://doi.org/10.1016/j. Fluorine Chemistry
jlluchem.2011.01.012

Nhlabathi, T.N., Nel, J.T., Puts, G.J., Crouse, P.L. 2012. Microwave digestion of zircon with ammonium acid fluoride: Derivation of kinetic parameters from nonisothermal reaction data. International Journal of Mineral Processing, 114 117, 35-39. https://doi.org/10.1016/j.minpro.2012.09.002.

Retief, W.L., Nel, J.T., Du Plessis, W., Crouse, P.L. 2014. Treatment of zirconia-based material with ammonium bi-fluoride. Google Patents 0011329 A1, assigned to South African Nuclear Energy Corporation Limited.

Rosales, G.D., Del Carmen Ruiz, M., Rodriguez, M.H. 2013. Alkaline metal fluoride synthesis as a subproduct of $\beta$-spodumene leaching. Hydrometallurgy, 139, synthesis as a subproduct of $\beta$-spodumene leaching. Hydr.
73-78. https://doi.org/10.1016/j.hydromet.2013.07.008.

Rosales, G.D., Del Carmen Ruiz, M., Rodriguez, M.H. 2016. Study of the Extraction Kinetics of Litium by leaching -Spodumene with Hydrofluoric Acid. Minerals, 6,98, 1-12. https://doi.org/10.3390/min6040098.

Sitando, O., Crouse, P.L. 2012. Processing of a Zimbabwean petalite to obtain litium carbonate. International Journal of Mineral Processing, 102, 45-50. https:// doi.org/10.1016/j.minpro.2011.09.014.

Wietelmann, U., Bauer, R. 2003. Litium and Litium Compounds. Ullmann's Encyclopedia of Industrial Chemistry, vol. 20. Wiley-VCH Verlag GmbH \& Co. Weinheim, Germany. 